\title{
Promessas e verbos páthicos na adolescência: uma possível releitura da moral e do supereu freudiano*1
}

\section{Promises and pathic verbs in adolescence: A possible reinterpretation of the Freudian moral and superego}

\author{
Hellen Fonseca de Sousa da Costa Vale*2 \\ Marta Helena de Freitas*3 \\ Francisco Moacir de Melo Catunda Martins*4
}

Neste artigo, abordamos a implicação e o papel dos verbos modais/ páthicos na construção das promessas e sua relação com as modalidades superegoicas da adolescência na atualidade. As promessas, no sentido em que as tomamos aqui, são entendidas como uma ação de comprometimento realizada via linguagem, podendo ser usadas como dispositivos efetivos para o entendimento das modalizações superegoicas do adolescente. O supereu, por sua vez, é percebido como o principal (des)organizador da modalização pulsional representada pelos verbos. Partimos do princípio de que o verbo carreia a pulsão e também monta o foro intrapsíquico humano, sendo assim, entender o modo como os adolescentes se referem aos verbos pode auxiliar a entender a respeito dos conflitos morais e pulsionais do adolescente construído frente à cultura atual.

Palavras chave: Adolescência, promessa, verbos páthicos, supereu

*1 Este artigo é parte da tese de doutoramento intitulada "Promessa e Clínica Psicológica com Adolescentes: - Impossibilidade ou necessidade?, defendida pela primeira autora no Programa de Doutorado em Psicologia da Universidade Católica de Brasília em 14/2/2020. A tese foi desenvolvida sob orientação da segunda autora e co-orientação do terceiro.

*2,3 Universidade Católica de Brasília - UCB (Brasília, DF, Brasi).

${ }^{* 4}$ Universidade de Brasília - UnB (Brasília, DF, Brasil). 


\section{Introdução}

Tendo em vista as mudanças paradigmáticas da nossa cultura atual e seus reflexos na construção psíquica dos adolescentes, o ato de prometer, enquanto ação de comprometimento realizada via linguagem, tem sido apontado como dispositivo efetivo para auxílio na clínica (Martins, 2003; Vale \& Martins, 2017). Sendo assim, neste trabalho pretendemos desenvolver em mais profundidade alguns pontos levantados anteriormente a respeito da importância do ato promissivo e do simbolismo da linguagem contida na promessa (Vale \& Martins, 2017). Apresentamos como novidade, na continuidade daquele trabalho, uma possível releitura da moral e do supereu freudiano via teoria dos verbos modais/páthicos de Weizsäcker (1947/2008), com vistas a possibilitar o entendimento dos modos de comprometimento do adolescente frente aos conflitos atuais e sociais, inerentes e constitutivos da própria fase.

Sabemos que somos seres de linguagem e emergimos na linguagem, portanto, é indispensável para os profissionais clínicos não tecnicistas entender e qualificar os atos estabelecidos por meio da palavra. Afinal, a linguagem simbólica é o meio pelo qual as pessoas, na vida e na clínica, expressam sua moral, seus sentimentos, suas angústias, deveres e desejos. E a promessa via linguagem simbólica, por sua vez, é a maior expressão de renúncia ao gozo imediato e também do ato civilizatório humano.

Martins (2002, p. 102) lembra que a promessa comporta um ato simbólico pleno, afirmando: "essa vertente da linguagem, a dimensão em que a pulsão pode se centrar no futuro, pode ser resumida em torno de uma palavra que a coloca como um ato simbólico pleno: a promessa" (p. 102). Desse modo, renúncia, futuro, adiamento, limite, lei e compromisso são ações que são inseparáveis dos atos promissivos. Realizar e cumprir uma promessa envolve todas essas ações, que também são tidas como 
condições necessárias para que o adolescente se torne adulto e sujeito social completo. Talvez por isso, hoje, tornar-se adulto venha sendo cada vez mais adiado, tendo em vista que a sociedade faz elogio ao imediatismo e ao prazer a qualquer custo (Ávila, 2011).

$\mathrm{O}$ ato simbólico da promessa envolve também uma relação íntima com os temas da moral e da ética. Prometer e cumprir exige do sujeito uma postura ativa em relação à ética e um emprego apropriado da própria moral. No que diz respeito aos conflitos de natureza ético-moral, Cortella e Barros Filho (2014) ressaltam que tais conflitos giram em torno da interrogação do Eu em relação aos verbos: Quero? Posso? Devo? Estes três verbos - o querer, o poder e o dever - e suas interarticulações, precedem o ato promissivo e permitem com que a promessa se realize ou não, na mente e na vida do adolescente. Sendo assim, priorizamos tais verbos em nossa investigação e os chamamos de verbos modais/páthicos, assim designados na teoria de Weizsäcker $(1947 / 2008 ; 1958)$. Percebemos que essa teoria, além de contribuir para aprofundar o estudo sobre a promessa, permite aprofundar os estudos sobre o supereu, e também possibilitar uma diferenciação mais apurada da escuta clínica, na qual devemos discriminar adequadamente os diversos componentes presentes na linguagem e suas expressões em frases.

Neste trabalho, então, teceremos uma discussão, de modo aprofundado, acerca dos verbos modais/páthicos de Weizsäcker (1962) e suas relações com a promessa, no sentido em que a define Martins (2003), e suas implicações para uma possível releitura da modalização superegoica, produto da sociedade de hoje. Para tanto, apresentamos os significados de promessas, verbos modais/páthicos e o que entendemos como modalização superegoica. A partir disso, estabelecemos a articulação entre verbos modais/páthicos e sua relação com as promessas na clínica psicanalítica e, por fim, apresentamos as características da adolescência atual e suas possíveis organizações modais, juntamente com as contribuições da promessa.

\section{Promessa, verbos páthicos e modalizações superegoicas}

Esclarece Martins (2002) que as palavras são essenciais e de suma importância para qualquer clínico, pois, além de tudo, elas podem ser expressões de compromisso e de verdade de consumação de atos futuros. São exemplos disso o contrato nas psicoterapias não tecnicistas entre a 
dupla terapêutica e, mutatis mutandis, o contrato social humano ou o pacto civilizatório.

Privilegiar as promessas efetivadas por meio de palavras é uma ação que vai na contramão da cultura atual. Aliás, chega a ser algo raro nos tempos de hoje. No entanto, estudiosos como Freud (1923/2011), Nietzsche (1887/2007) e Lévi-Strauss (1982) já sinalizam sobre a importância de tal ato. Assim, para Lévi-Strauss (1982), por exemplo, as promessas são o que sustentam o contrato social. São a contrapartida positiva do Édipo.

Ou seja, no simbolismo da promessa, via linguagem, é possível uma relação entre atos presentes e perspectivas futuras, entre interdição, renúncia e novas possibilidades. Como no complexo de Édipo, em que há a interdição da lei e a renúncia ao desejo. Mas, há também a contrapartida, que se apresenta por uma abertura de outras possibilidades. Isto é, mesmo no tabu do incesto, existe o contraponto da prescrição, ou seja, existe uma promessa. Desta forma, por exemplo, não se pode manter relações sexuais com a mãe e as mulheres de consanguinidade próxima, mas pode com todas as outras, evidenciando a importância do ato simbólico que as promessas representam para a consolidação do pacto civilizatório (Lévi-Strauss, 1982). Então, para o 692 antropólogo, a cultura, simbolicamente e por meio da linguagem, pode nos oferecer mais promessas do que interdições e renúncias.

Retomando o significado etimológico da palavra promessa, observamos que há uma relação com o tempo futuro, mas também há ações que são necessárias no tempo presente. Como nos informa o Dicionário Priberam (2008-2013), a palavra vem do "latim promissa", e tem como principais significados: 'enviar para diante', 'deixar ir para diante', 'deixar crescer', 'garantir', 'assegurar'. Ou 'Acordo, oral ou escrito, em que as partes se obrigam a cumprir o estabelecido - compromisso'.

Portanto, obrigação, renúncia, cumprimento de palavra, acordo, voto, compromissos, são atos que envolvem uma promessa e podem ser estabelecidos e exercidos por meio de palavras. A promessa via palavra é a maior expressão do simbólico que pode ser expresso através da linguagem. No entanto, é necessário se ter ascendido ao simbólico para que a pessoa consiga prometer ou entender sobre o prometido. Uma criança muito pequena, por exemplo, não acompanha cognitivamente todas as peripécias da linguagem e ainda não tem a estrutura do tempo montada na mente. Então, não entende os significados e os sentidos simbólicos das palavras e das promessas. Os adolescentes, com muito mais propriedade, sim, por já terem alcançado a compreensão e o domínio nas etapas do processo de aquisição da linguagem (Astington, 1988a, 1988b). 


\section{ARTIGOS}

Então, as promessas são realizadas por meio de palavras. A palavra é a verbalização de uma promessa realizada mentalmente. Mas antes que o ato promissivo aconteça, há uma interação modalizadora interna. Ou seja, a pessoa em seu fórum intrapsíquico decide prometer ou não prometer, o que consequentemente envolve a articulação entre os verbos: quero, posso, devo? Portanto, os verbos modais no foro intrapsíquico precedem o ato promissivo na relação com o outro.

Gramaticalmente falando, verbo, de acordo com o Dicionário Houaiss da Língua Portuguesa (2009, p, 1933), é uma classe de palavras que contém as noções de ação, processo ou estado. Eles apresentam categorias, como o tempo que indica se algo já aconteceu, está acontecendo ou vai acontecer e o modo - subjuntivo, indicativo e imperativo - que indica a atitude sobre o fato enunciado pelo falante, que pode ser de certeza, temor, dúvida, desejo, ordem etc. O modo é a introdução do $\mathrm{Eu}$ da anunciação, da categoria de pessoa que possibilita um aspecto pessoal da linguagem.

Dentro da categoria dos verbos, temos os verbos modais, que traduzem as modalidades de ação, modalizam o enunciado e mudam o significado dos verbos de ação. São aqueles que, dentro da classe gramatical, só existem na mente humana. Os modais necessitam de um complemento para que o sentido da frase seja alcançado. Como tal, eles especificam ou modulam o sentido do verbo principal no intuito de expressar uma ideia particular. Ou seja, eles não podem ser representados imageticamente, tal como os verbos de ação correr, pular, no entanto, eles modificam o sentido da ação (Bechara, 2009).

Não obstante, quando o verbo modal vem conectado com um pronome, o chamamos de verbo páthico, tendo em vista que o sujeito se distingue pela forma de engajamento no verbo. Assim, o páthico acontece quando o autor da fala conecta uma pessoa gramatical ao verbo dito. Ou seja, os verbos páthicos implicam sempre o sujeito nos seus atos. Desse modo, por exemplo, é diferente, do ponto de vista da enunciação, quando nos remetemos ao verbo poder ou dever de forma impessoal ou generalizada e quando dizemos de forma pessoalizada 'eu posso' ou 'eu devo'. Quando o pronome 'eu' vem conectado ao verbo, há um engajamento da pessoa na palavra e, consequentemente, no ato. Então os verbos páthicos são os verbos modais acompanhados de uma pessoa gramatical, sendo que ele somente se efetiva se a pessoa decidir agir, assim como na promessa (Martins, 2012).

Os verbos modais/páthicos possibilitam a ação na mente e na linguagem e os tempos e modos verbais possibilitam o movimento, o ritmo e o tempo da ação. Por conta disso, eles se relacionam com a pulsão, como nos informa 
Antônio (2016). A pulsão é algo que vai se modificando, se constituindo, está em constante movimento, de maneira nenhuma é estática ou exata e concreta. Sendo assim, vida mental e movimento pulsional estão interligadas (Schotte, 1985).

Freud (1917/1996c) relaciona a pulsão ao supereu. Enfatiza o excesso pulsional exigido pelo supereu quando fala sobre o processo melancólico. No entanto, o conceito de supereu apresenta diversos paradoxos. Em Freud (1933/1996d, p. 72), temos o supereu com a conotação de "representante de todas as restrições morais" e "advogado de um esforço tendente à perfeição". Seria um proibidor da satisfação pulsional e aquele que impõe limites ao gozo. Diferentemente do supereu em Lacan, que é justamente o ordenador do gozo que o supereu freudiano proíbe (Gerez-Ambertín, 2009). No entanto, apesar de haver controvérsias conceituais sobre o supereu, nosso intuito não é o de apresentar um antagonismo entre Freud e Lacan e nem compreender o conceito de forma a fechá-lo, correndo o risco de restringir e perder grande parte de sua riqueza conceitual. Aqui, buscamos utilizar o entendimento sobre promessas e sua construção através dos verbos modais, a fim de contribuir para um melhor entendimento da instância moral e sua expressão nos atos de adolescentes.

Estamos interessados em apontar como que a promessa, o verbo modal/ páthico e o superego são conceitos que têm como base principal a linguagem e permitem um entrelaçamento entre si. Eles são reestruturados na vida e na mente do sujeito durante a adolescência e, por isso, merecem uma atenção especial do clínico. Escutar de maneira atenta aos elementos que compõem a frase é papel daquele que se propõe investigar a mente humana. Afinal, no processo de escuta clínica, não podemos tratar da mesma maneira os diferentes elementos da frase. Verbos, substantivos, adjetivos, pronomes e os demais componentes são distintos uns dos outros. Os verbos, sejam eles modais ou não, são palavras variáveis e são o coração da ação, podendo variar em tempo, modo, número e pessoa. Por isso, privilegiamos a escuta dos verbos. Pois, assim como pulsão é ação, verbo também é ação. Portanto, diante da interarticulAção entre os verbos posso, quero e devo, podemos entender como está estruturada a relação do sujeito com as promessas e os compromissos e, consequentemente, sua estruturação modal superegoica diante dos conflitos éticos/morais.

O verbo é o que designa a ação e possibilita a atividade de existência e experiência na linguagem e na mente humana. Desse modo, percebe-se que a atitude da pessoa está ligada ao sistema gramatical do modo verbal. Os verbos modais e páthicos, internamente, precedem a enunciação das promessas e 


\section{ARTIGOS}

dos processos decisórios, mas também, ao se interaticularem, compõem o movimento pulsional e superegoico humano.

\section{Verbos modais/páthicos e sua relação com as promessas na clínica psicanalítica}

Retomando o papel específico dos verbos modais/páthicos e sua presença no contexto clínico, destacamos suas características de serem vividos/ expressos pela pessoa tanto em sua intralocução quanto em sua interlocução. As características gramaticais desses verbos podem ser colocadas em diálogo com as contribuições freudianas em torno da importância dos verbos em contextos clínicos (Freud, 1913/1996b). De fato, segundo o pai da psicanálise, os verbos são tão relevantes na clínica, que ele chega a reafirmar a fala de Goethe "no princípio era a ação", corroborando a ligação do verbo com a pulsão (Freud, 1913/1996b, p. 102). Ora, verbo é ato! Além de o verbo ser o único componente da frase que representa a ação, ele também é um dos únicos elementos que oferece a noção de tempo. Portanto, os atos mentais, impulsionados pelos verbos modais/páthicos, podem direcionar os atos operados no mundo concreto.

Sendo assim, via linguagem, no presente do indicativo, podemos prometer atos que levarão ao cumprimento daquilo que foi prometido presentemente, no futuro. A promessa é um ato de linguagem, do qual é precedido por um processo decisório que acontece internamente no foro intrapsíquico envolvendo os verbos quero, posso e devo. A linguagem que participa dos processos decisórios ypseitas é a mesma que participa da formação do contrato social. Nos dois processos, a linguagem é carregada de verbos que carreiam o movimento pulsional e moral dos seres humanos.

O movimento moral e pulsional, na língua portuguesa, podem ser expressos pelas categorias páthicas através de três verbos que se desdobram em cinco sentidos, são eles: querer como vontade voluntária; poder como permissão; poder como ter capacidade; dever como dever ético/moral; e dever como ser necessário.

O Quadro 01 apresenta os verbos distribuídos de forma a possibilitar melhor entendimento dos seus diversos sentidos no contexto da linguagem e sua expressividade no mundo da vida e no contexto clínico. 
Quadro 01 - Categorias Páthicas

\begin{tabular}{|l|l|l|l|}
\hline Verbo & \multicolumn{1}{|c|}{ Sentido } & Alemão & Inglês \\
\hline Querer & Desejar efetivando no indicativo & Wollen & To want \\
\hline Poder & Permissão moral, licença para, desafiar, ousar & Dürfen & May \\
\hline Poder & $\begin{array}{l}\text { Capacidade natural; ser capaz de } \\
\text { ter a faculdade para }\end{array}$ & Können & Can \\
\hline Dever & Obrigação ético/ moral, ter de & Sollen & Should \\
\hline Dever & Necessidade; haver de, precisar de & Müssen & Must \\
\hline
\end{tabular}

Apresentamos os verbos nas três línguas a fim de exemplificar as diferentes palavras designadas para cada um. No alemão, por ser a língua de escrita principal de Freud e Weizsäcker, e no inglês, para complementar as especificidades e os sentidos de dos cinco verbos modais. Para melhor explicitarmos seus sentidos em português, lançamos mão de conceitos extraídos do dicionário etimológico da língua portuguesa (Machado, 1987), 696 do dicionário Houaiss da língua portuguesa (Houaiss, 2009), assim como dos textos de Schotte (1985) e Martins (2012). Esmiuçando o Quadro, temos:

Querer (Wollen): o querer é ativo e, no entanto, se faz uma categoria páthica. Ele ocupa uma posição central, mas não privilegiada. Existe um paradoxo central: um querer querido, que a faz como uma espécie de paixão, uma pathia.

O querer é atravessado pelo dever e pelo poder, de modo que a oposição entre o natural e moral sempre se farão presentes nos mesmos: poder moral (dürfen), dever natural (müssen), dever moral (sollen) e poder como capacidade inerente (können). Querer é ter a intenção ou vontade de; procurar obter, obter, conseguir, arranjar, procurar saber, inquirir.

Pode (Dürfen): é o poder como ter permissão para, é poder algo, ousar. Ter coragem de se lançar com ousadia. Usado para pedir alguma coisa; ter influência; ousar; permitir-se; poder sobre alguém; ter moral; valimento.

Poder (Können): é a categoria do poder natural, capacidade. O possível que ultrapassa o permitido, o obrigatório; poder natural. Ter faculdade de; ter possibilidade de; ter capacidade para.

Dever (Sollen): o dever no sentido de obrigação moral. Mas não se deve pensá-lo de maneira a representar instâncias éticas substantivadas, como a 


\section{ARTIGOS}

moral, o superego. É ter obrigação de; estar obrigado a; em débito. É ter de. É dinâmico.

Dever (Müssen): do dever, da necessidade. Tomado pela ideia de necessidade sem liberdade, mas sim somente maquinação obrigatória a ser executada a todo custo de vida. Ideia natural de uma necessidade a ser completada.

Tais verbos representam um novo campo de investigação que o médico alemão Weizsäcker inaugura (1958). Com esse pensamento, o autor apresenta um novo paradigma, a medicina antropológica, que é pautada em uma metodologia dialética entre o equilíbrio-desequilíbrio. Tal metodologia implementa um olhar clínico e dinâmico ao campo das investigações da existência e do estado mental dos seres humanos. Esse novo formato é o que dá a base para a concepção do pentagrama páthico, pois é a partir dele que as pessoas irão comunicar seu mundo interno, seus conflitos subjetivos e existenciais.

Para Weizsäcker (1958), o modo páthico é um sistema de funcionamento volitivo. O sistema de funcionamento é representado pelo pentagrama reproduzido na Figura 01.

Independentemente da disposição, o modelo estelar apresenta uma interarticulação entre todas as categorias verbais para demonstrar a constituição da civilização da pessoa. Então, temos cinco tipos de ações ou modos de ser distintos, pertencentes ao mesmo sistema. De acordo com Rezer

Figura 1: Pentagrama Páthico.

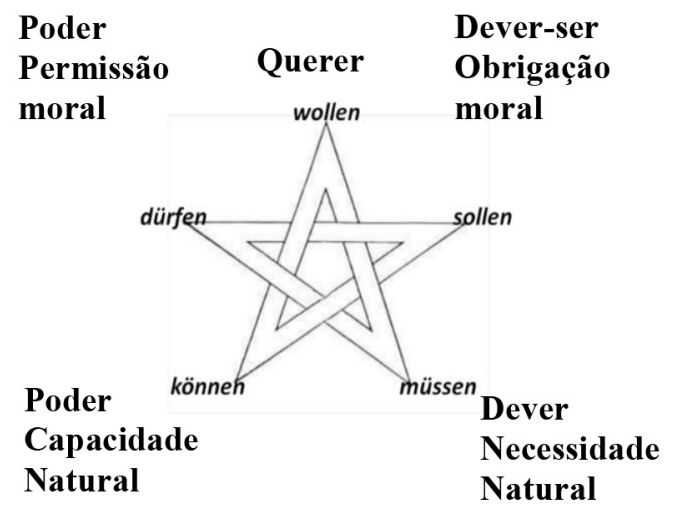

Adaptado de Martins e Costa Neto (2015) 
e Reggio (2013, p. 26), o que Weizsäcker (1958) considera ser categorias páthicas são "unidades volitivas arraigadas do Ser". Tais unidades se manifestam de diversas maneiras: "Algumas vezes superando possibilidades da existência, outras rareando, conforme estados de desequilíbrio ou doença". No seu conjunto, elas "formam a estrutura da forma da vida e da personalidade" (p. 26).

Não obstante, os verbos páthicos querer, poder e dever são especificamente humanos e representam a existência. "Cada verbo modal pode ser dividido, pessoalizado e personalizado. Em seu uso e articulação podemos ver como a personalidade humana é estruturada" (Weizsäcker, 1945/1987, p. 386). Ou seja, para o clínico alemão, toda e qualquer decisão é eminentemente tomada a partir do poder, do dever e do querer. Mas sempre implicando um sujeito em liberdade de escolha e de pensamento. Um sujeito que possa ser responsável por si e pela sua escolha.

Nietzsche (2007, p. 52) apresenta o homem superior ou supramoral como homem responsável, aquele que é confiável, que pode prometer que terá o poder enquanto ousadia e capacidade para cumprir. No entanto, para que uma pessoa consiga prometer, ela precisa antes entender sobre o pedir. Percebemos que a ponta esquerda da estrela precede a ponta direita em sua construção. O próprio contrato e tratamento psicanalítico é montado sobre o poder como pedir e o dever como ter obrigação de, que são as duas pontas superiores da estrela, da qual chamaremos de vertentes epistêmicas. Epistêmica no sentido civilizatório, reflexivo, mais elaborativo, menos impulsivo, menos arcaico e menos primitivo.

A análise começa com o modal poder (dürfen) e sua articulação com o dever (sollen), a partir da renúncia e do recalque. Ou seja, o começo da análise, assim como um jogo de xadrez, depende da aceitação de regras previamente estabelecidas (Freud, 1913/1996b, p. 123). É condição saber o que se pode, o que se deve, o que não se pode e o que não se deve, antes e durante a partida. Por exemplo, o paciente deve ir às sessões, deve pagar, pode falar, mas não pode agredir, machucar ou destruir, em ato concreto, o consultório do terapeuta. Portanto, poder e dever são dois verbos que permitem a arte de fazer análise e também de tornar-se pessoa. Conforme explicitado na Figura 02:

Tornar-se pessoa está relacionado ao processo do Eu em sua interação com a modalização. $\mathrm{O} \mathrm{Eu}$, em sua modalização, expressa a liberdade e a força do recalque, ou seja, o mal-estar na civilização. Tornar-se pessoa está vinculado a autorresponsabilização e a autonomia do sujeito. Tanto 

pelas autoras.

Figura 2: Representação gráfica da disposição epistêmica dos verbos envolvidos na análise. Produzidas

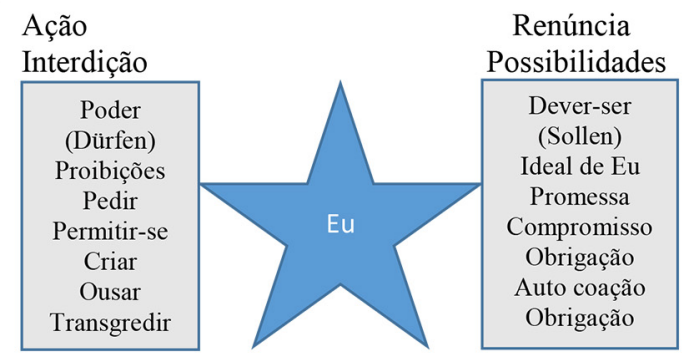

Poder como capacidade

Dever Necessidade

socialmente quanto emocionalmente. Tornar-se pessoa envolve compromissos, deveres, renúncias e até obrigações.

No entanto, antes de entender de renúncias, deveres e obrigações, é necessário que a pessoa saiba o que é poder, pedir, permitir-se, criar, ousar. Então, o pedir (dürfen) é fundamental para que haja o dever, o compromisso e a promessa. Para aquele que se compromete, é necessário primeiro que saiba pedir. Somente sustenta uma promessa quem pede. O pedido é pré-condição para o prometer, sendo que, na aquisição dos verbos da estrela, na mente da pessoa, o pedido vem antes. Isto é, o poder é mais primário que o dever-ser. $\mathrm{O}$ dever-ser começa a se fazer presente somente no final do quinto ano de vida, como experiência de consecução do prometer. O pedir se inicia antes, por volta dos primeiros dois anos. Quando a criança já tem a posse do verbo pedir, ela já consegue pedir, mesmo que seja através do olhar (Martins, 2015).

Contudo, para prometer, diante da dialética dos verbos, é necessário que a pessoa se responsabilize pelo seu processo decisório, atinja o mínimo de autonomia e se sinta livre (no sentido estrito do termo) para estabelecer as suas escolhas. Ou seja, a montagem da ponta direita da estrela, a ponta do dever e da promessa, se dá por último, quando a pessoa se encontra em um nível em que a estrutura da aquisição dos outros verbos já está instalada na mente, já está internalizada. Inicialmente, a montagem da modalização interestelar se dá através das pontas de baixo, somente sendo possível a pessoa saber sobre dever, renúncia e obrigação a partir da forma como foi estruturado o dever como ser necessário e o poder como ter capacidade. Só a partir das pontas inferiores da estrela, a pessoa deixa de ser para vir a ser, passa da ordem do natural para a ordem do moral. 
Tendo em vista a construção do psiquismo moral do adolescente, as promessas para se efetivarem como tal, são precedidas pela interarticulação dos verbos modais/páthicos. Ou seja, a forma como o sujeito modaliza a sua ação, podendo então informar o modo como ele está engajado no mundo diante dos desejos e deveres. $\mathrm{O}$ entendimento dessa modalidade pode auxiliar o clínico a lidar com o adolescente atual.

\section{Adolescência atual e possíveis organizações superegoicas: contribuições da promessa via verbos páthicos}

O período adolescente, resguardado todas as especificidades culturais de cada época, sempre foi um momento de confronto com a alteridade. Contudo, a adolescência que nos interessa é um fenômeno dos últimos 60 anos. Neste contexto, ela é vivenciada a partir de três modalidades: 1) fase do desenvolvimento calcada na faixa etária; 2) estado de espírito (Pathos); e 3) ideal cultural. Faixa etária, porque é acompanhada de mudanças biológicas que emergem na transição entre um corpo infantil e um corpo adulto. Estado de espírito, porque não se reduz à pubescência, e comporta determinado modo subjetivo de estar no mundo. Ideal cultural, porque hoje a adolescência encarna o maior sonho de nossa cultura, o sonho de liberdade. Enquanto a infância proporciona aos adultos uma promessa de imortalidade, continuidade e consolação para o fim de tudo (a morte), a adolescência, hoje, fantasiosamente proporciona uma promessa de liberdade sem responsabilidade, de gozo imediato, de prazer sem limites (Calligaris, 2003).

De modo individualizado, diante da reatualização daquilo que foi adiado pelo recalcamento na latência, o adolescente busca tonar-se pessoa. A adolescência é também uma busca pelo vir a ser. Contudo, as mudanças ocorridas durante o século XX, deslocaram a figura do pai e a sua função na hierarquia familiar, o que torna o trabalho da adolescência mais difícil ainda, pois exige do adolescente um esforço a mais. Freud sempre aprendeu com os sintomas de sua época, os quais, diga-se de passagem, eram muito diferentes dos atuais. Hoje, os sintomas estão calcados nos acenos que os adultos fazem aos adolescentes, oferecendo implicitamente promessas ilusórias de prazer sem limites a ponto de fazer elogio ao fato de burlar até a castração (Rocha \& Garcia, 2008).

Os resultados são: os modelos a serem imitados são os dos adolescentes. Além de o adolescente poder realizar tudo o que quiser, os adultos ainda 


\section{ARTIGOS}

podem querer ser adolescentes. $O$ poder sem o dever, o desejo sem a obrigação. Ou seja, adolescentes como adultos de férias, sem lei, tornam-se o ideal cultural mais almejado pela sociedade líquida (Bauman, 2001; Calligaris, 2003). Pensar em tais aspectos permite um melhor entendimento sobre a articulação das demandas atuais com as novas modalidades de sofrimento humano presentes na clínica psicopathológica.

$\mathrm{Na}$ adolescência, pode ocorrer a retrodesconstrução dos sintomas e das sublimações (ruckgebildet) que foram efetivadas até então, no decorrer das fases constituintes da pessoa do adolescente (Freud, 1905/1980). Não obstante, a psicanálise não enxerga o desenvolvimento das fases de forma generalista. Aqui a clínica sempre é soberana em relação à teoria e aos diagnósticos. Apesar disso, a prática nos ensina que acontece mais comumente de os adolescentes se perderem em meio às inversões edípicas do que tentarem evitá-las. Ou seja, as questões de base ligadas à identificação são primordiais na construção do psiquismo moral na adolescência. E como pensar as questões de identificação na sociedade de hoje, da qual as normas éticas, valores e leis são movidos a relativização?

Ora, durante a tentativa de desidentificação das figuras parentais infantis, pode acontecer de o adolescente se perder em meio à operação de inversão edípica. Isto é, a adolescência demarca a inversão dessa operação, na medida em que o que se conseguiu apurar em identificação deve dar lugar novamente ao amor. Enquanto a infância realiza o trabalho de transformar amor em identificação, a adolescência realiza o contrário, as identificações servem de base e são relegadas a um segundo plano para que a escolha do amor objetal venha acontecer (Corso, 2002).

No entanto, na atualidade, podemos perceber uma crise nas identificações no momento da adolescência. Esse momento exige também uma reorganização do psiquismo moral. Atualmente, parte dos jovens têm o ideal, mas não querem a obrigação; outra parte tem certas obrigações, mas o ideal está impedido por sintomatologias, características frequentes do mundo contemporâneo, em que as referências simbólicas se encontram verdadeiramente capengas. Então, mais uma vez, as formas sociais atuais acabam por influenciar a interarticulação modal e moral do adolescente.

$\mathrm{O}$ adolescente vivencia um processo de busca de si mesmo, tentando reformular e reparar remanescentes edípicos que ficaram mal resolvidos, ao mesmo tempo que o lugar e as normas às quais os adolescentes estão expostos formam seus sistemas de referências. A adolescência possibilita uma segunda oportunidade de lidar com as problemáticas instauradas na infância. Só que, 
agora, com um corpo erógeno pulsionalizado, pronto para realizar o ato sexual (Freud, 1905/1980), aumentando a oposição e o conflito entre querer, poder e dever. Deste modo, ao levar todos esses aspectos em consideração, entendemos que, no discurso, o emprego dos verbos páthicos são indicadores de determinadas posturas.

Cabe ressaltar, que para Weizsäcker (1947/2008, p. 97), as categorias páthicas não são estáticas ou cíclicas, e sim, circulares. Elas não são algo que se tem, mas sim, algo do qual se padece (erleidet). Hoje, padecemos pelos excessos. Excesso de querer, de poder e de dever. Contudo, o funcionamento das categorias páthicas se dá a partir de uma configuração dialética, em que somente no $a$ posteriori podemos saber qual categoria foi privilegiada pela pessoa.

Sendo assim, a análise do modo de circulação das categorias páthicas pode nos proporcionar uma forma de compreensão das construções superegoicas do adolescente, frente a uma modalidade cultural que tem como promessa a realização do ideal via imperativo do gozo. Então, como fica o trabalho psicológico diante de um supereu que, na prática, vai perdendo a modalidade de uma instância que também exige renúncia pulsional e ganha espaço apenas como imperativo do gozo, custe o que custar? (Lacan, 1971/2009).

Sabemos que na época de Freud a sociedade era pai orientada, haviam prerrogativas que cabiam apenas aos pais ou aos mais velhos, como a questão do sexo, por exemplo. Os adultos se preocupavam, sobretudo, se os adolescentes estavam ou não tendo relações sexuais. À época estava bem delimitado o que os adolescentes não podiam e não deviam. Hoje isso mudou. O querer parece que impera sobre o poder e, sobretudo, sobre o dever, como obrigação e renúncia. Além disso, o limite do "não" está em desuso, contribuindo ainda mais para que o adolescente fique relegado aos seus próprios desejos.

Na visão de Winnicott (2005a), “os adolescentes têm sim prblemas com os instintos; no entanto, mais importante do que isso, é que eles querem ser alguém em algum lugar" (p. 123). Querer "ser alguém em algum lugar" é algo que perpassa a construção de adolescentes de diferentes épocas. Entretanto, o psicanalista fala que é necessária uma provisão ambiental que possibilite cuidados característicos ao adolescente. Ou seja, necessita de um ambiente confiável, estável, seguro, e que saiba reconhecer as suas necessidades, ao mesmo tempo que o contém e delimita, possibilitando o holding (Winnicott, 2005b).

No formato social atual, onde tudo é muito efêmero e líquido, acontece também uma mudança na provisão ambiental referida pelo autor, e que 


\section{ARTIGOS}

contribui para potencializar certas características negativas e até psicopathológicas ao adolescente no processo de tornar-se adulto. $\mathrm{O}$ autor chama a atenção para o fato de que "existe somente uma cura real para a adolescência: o amadurecimento" (Winnicott, 2005a, p. 163). Tal amadurecimento pode ser alcançado a partir do formato da articulação verbal na vida e na mente do adolescente. Ora, aquele que faz promessas, e se compromete, aceita o sacrifício e a renúncia ao gozo imediato, que é próprio do ato promissivo. A promessa é o ato pulsional levado ao futuro. Sendo assim, as pulsões são moldáveis e os verbos moldam o destino pulsional e também a articulação moral.

A emissão da promessa vale como uma obrigação assumida (Searle, 1969/1984). Nas línguas latinas, cumpre-se em seu aspecto duplo, o do compromisso e o da obrigação. Sendo o compromisso relacionado ao ideal do eu e a obrigação relacionada ao supereu crítico. Contudo, o eu é tanto emissor quanto receptor de ordens na forma de obrigações contraídas pelo compromisso com o ideal e com o supereu. Além de tudo, como dissemos, a promessa é o que esteia o dever-ser, que está relacionada com o supereu e o ideal de eu Martins e Costa Neto (2015). A promessa, e todos os aspectos que a envolve, pode auxiliar o adolescente no processo de amadurecimento e de tornar-se pessoa.

Desse modo, um dos grandes problemas da adolescência é o supereu e suas modalizações, posto que, na infância, o supereu estava modalizado de forma característica ao infantil e, de repente, na reedição do complexo edípico na adolescência, com o recrudescimento de outra moral e de outros ideais, essa modalização muda. Então, não mais está clara, para o adolescente, a relação mental entre os verbos modais poder, dever e querer, como era na infância. Aqui, cabe uma citação de Freud (1910/1996a, pp. 199-200) que exemplifica o conflito gerado na adolescência pela atuação e oposição entre os verbos modais: "a oposição entre as ideias (Vorstellungen) é apenas uma expressão das lutas entre os vários instintos (Trieb) ".

Portanto, entendemos que o foro intrapsíquico e o supereu, onde estão localizadas a ética, a moral e as leis sociais, ambos ligados à linguagem, são montados pelos verbos modais. Ou seja, o que Freud já havia prenunciado quando, em 1923, descreve a relação censora do supereu com o eu. Em sua fala aponta os dois lados da estrela dos verbos modais que controlam o supereu, conforme se segue:

Mas o Supereu não é simplesmente um resíduo das primeiras escolhas objetais do id; possui igualmente o sentido de uma enérgica formação reativa a este. Sua relação com o Eu não se esgota na advertência: "Assim (como o 
pai) você deve ser"; ela compreende também a proibição: "Assim (como o pai) você não pode ser, isto é, não pode fazer tudo o que ele faz; há coisas que continuam reservadas a ele" (Freud, 1923/2011, p. 42)

Nota-se que, na asserção freudiana, "você deve ser assim e você não pode ser assim", encontramos dois verbos modais superegoicos, o dever e o poder, denotando então a existência daquilo que foi denominado genericamente, por Freud, como censura. De acordo com a citação acima, para Freud, o que se deve, deriva do que se pode. Tal afirmativa está em consonância com a teoria dos verbos modais/páthicos de Weizsäcker (1947/2008) e de Martins e Costa Neto (2014).

Deste modo, do ponto de vista clínico, entender a maneira como o adolescente lida com a articulação dos verbos que precedem as promessas e aos compromissos pode informar o modo como ele está organizado no mundo diante dos conflitos pulsionais e éticos-morais.

\section{Considerações finais}

A adolescência como uma reedição dos conflitos infantis por si só já pode gerar desconfortos e desordens ao adolescente e ao meio. O modo de organização social pode potencializar ou produzir outros modos de adoecimentos para além do que já é característico da própria fase. A sociedade atual, reconhecida como a sociedade do espetáculo, vem formando sujeitos adoecidos e com características diferentes das sociedades anteriores. $\mathrm{Na}$ tentativa de contribuir para um melhor entendimento dos novos modos de organização e sofrimentos humanos, este trabalho buscou qualificar temas que são pouco falados na realidade atual, como promessas, compromissos, deveres, obrigações e renúncias, via verbos que configuram as organizações morais superegoicas e possíveis processos decisórios no adolescente.

Em psicanálise, entendemos que o destino de cada um é condicionado pelo conflito pessoal entre as pulsões, o supereu, e o eu, inimigo pulsional. A análise do destino de Szondi (1975) ensina-nos, por exemplo, que estar "mau" ou "mal" significa não ter encontrado ainda a saída de emergência apropriada ou adequada para os impulsos negativos. Ora, a investigação do movimento pulsional via verbos páthicos pode facilitar a compreensão do processo mental e existencial do adolescente, na clínica psicanalítica, favorecendo o trabalho 


\section{ARTIGOS}

no encontro de saídas mais apropriadas face às emergências encontradas na clínica da contemporaneidade.

Sendo assim, ainda que limitado e tendo um seu valor mais a título de provocar reflexões acerca da importância da qualificação de temas óbvios e necessários ao amadurecimento - como a promessa, por exemplo, esperamos que este trabalho tenha permitido a abertura para novos olhares no que tange à construção da moral e dos processos decisórios humanos, em especial durante a adolescência.

\section{Referências}

Antônio, P. S. (2016). O estoma: investigação psicanalítica-existencial do sofrimento psíquico e sua modalização. Tese de Doutorado em Psicologia Clínica e Cultura, Universidade de Brasília, Brasília, DF, Brasil. Recuperado de: $<$ https://repositorio. unb.br/handle/10482/21754>.

Astington, J. W. (1988a). Children's understanding of the speech act of promising. Journal of Child Language, 15, 157-173.

Astington, J. W. (1988b). Children's production of commissive speech acts. Journal of Child Language, 40, 411-423.

Ávila, L. A. (2011). Adolescência sem fim. Vínculo, 8(1), 40-45. Recuperado em 14 out. 2019, de: <http://pepsic.bvsalud.org/scielo.php?script=sci_ arttext\&pid=S1806-24902011000100007\&lng=pt\&tlng=pt $>$.

Bauman, Z. (2001). Modernidade líquida. Rio de Janeiro, RJ: Jorge Zahar.

Bechara, E. (2009). Moderna gramática portuguesa. $37^{\mathrm{a}}$ ed. revista, ampliada e atualizada conforme o novo Acordo Ortográfico. Rio de Janeiro, RJ: Nova Fronteira.

Calligaris, C. (2003). Adolescência. São Paulo, SP: Publifolha.

Corso, D. M. L. (2002). Édipo, latência e puberdade: a construção da adolescência. Revista da Associação Psicanalítica de Porto Alegre, 23(10), 18-30. Recuperado em 17 jul. 2017, de: <www.appoa.com.br>.

Cortella, M. S. e Barros Filho, C. de. (2014). Ética e vergonha na cara. Campinas, SP: Papirus.

Dicionário Priberam da Língua Portuguesa [on line]. Verbete promessa. (2008-2013). Recuperado em 10 dez. 2019, de: <https://dicionario.priberam.org/promessa>.

Freitas, A. L., \& Rudge, A. M. (2011). O supereu entre o amor e o gozo. Tempo psicanalitico, 43(2), 244-267. Recuperado em 5 dez. 2019 de: <http://pepsic. bvsalud.org/scielo.php?script=sci_arttext\&pid=S0101-48382011000200001\&ln $\mathrm{g}=\mathrm{pt} \& \operatorname{lng}=\mathrm{pt}>$. 
Freud, S. (1980). Três ensaios sobre a teoria da sexualidade. In Edição Standard Brasileira das Obras Psicológicas Completas de Sigmund Freud (Vol.VII). Rio de Janeiro, RJ: Imago. (Trabalho original publicado em 1905).

Freud, S. (1996a). A concepção psicanalítica da perturbação psicogênica da visão. In Edição Standard Brasileira das Obras Psicológicas Completas de Sigmund Freud (Vol. XI, pp. 199-200). Rio de Janeiro, RJ: Imago. (Trabalho original publicado em 1910).

Freud, S. (1996b). Totem e tabu. In Edição Standard Brasileira das Obras Psicológicas Completas de Sigmund Freud (Vol. XIII, pp. 11-191). Rio de Janeiro, RJ: Imago. (Trabalho original publicado em 1913).

Freud, S. (1996c). Luto e melancolia. A história do movimento psicanalítico: artigos sobre metapsicologia e outros trabalhos. In Edição Standard Brasileira das Obras Psicológicas Completas de Sigmund Freud (Vol. XIV, pp. 249-263). Rio de Janeiro, RJ: Imago. (Trabalho original publicado em 1917).

Freud, S. (1996d). Conferência XXXI: A dissecção da personalidade psíquica. In Edição Standard Brasileira das Obras Psicológicas Completas de Sigmund Freud (Vol. XXII, pp. 63-84). Rio de Janeiro, RJ: Imago. (Trabalho original publidado em 1933).

Freud, S. (2010). O início do tratamento. In Obras Completas (Vol. 10, pp. 164-192). São Paulo, SP: Companhia das Letras. (Trabalho original publicado em 1913).

Freud, S. (2011). O Eu e o Id, autobiografia e outros textos (Vol. 16). São Paulo, SP: Companhia das Letras. (Trabalho original publicado em 1923).

Gerez-Ambertín, M. (2009). As vozes do supereu na clínica psicanalítica e no mal- estar na civilização. Rio de Janeiro, RJ: Cia. de Freud.

Houaiss, A., Villar, M. de S., \& Franco, F. M. de. (2009). Dicionário Houaiss da Língua Portuguesa. Rio de Janeiro, RJ: Objetiva.

Lacan, J. (2009). O seminário. Livro 18. De um discurso que não fosse semblante. Rio de Janeiro, RJ: Zahar. (Trabalho original publicado em 1971).

Lévi-Strauss, C. (1982). Estruturas elementares do parentesco. (9a ed.). Petrópolis, RJ: Vozes

Machado, J. P. (1987). Dicionário etimológico da língua portuguesa. $3^{\mathrm{a}}$ ed. Lisboa, PT: Livros Horizonte.

Martins, F. (2002). O complexo de Édipo. Brasília, DF: Editora Universidade de Brasília.

Martins, F. (2003). Promessa e psicoterapia. Psicologia em Revista, 9(13), 67-75.

Martins, F. (2012). O pensamento do clínico. [Texto inédito].

Martins, F., \& Costa Neto, A. A. (2014). Violência no morro! In M. de Souza, F. Martins, \& J. N. Garcia de Araújo (Orgs.), Violência e figuras subjetivas: investigações acerca do mal inconsolável (pp. 249-266). Florianópolis, SC: Editora UFSC. 
Martins, F., \& Costa Neto, A. A. (2015). O pentagrama pathico de Weizsäcker. In M. I. G. Conceição, M. I. Tafuri, \& D. S. Chatelard (Orgs.). Psicologia clínica e cultura contemporânea 2. (pp. 617-627). Brasília, DF: Technopolitik Editora.

Nietzsche, F. (2007). Além do bem e do mal. São Paulo, SP: Companhia das Letras. (Trabalho original publicado em 1887).

Nietzsche, F. (2017). Genealogia da Moral - uma polêmica. São Paulo, SP: Companhia das Letras.

Rezer, R., \& Reggio, D. J. (2013). Concepções fillosóficas para o campo da saúde: um diálogo com Gadamer e Weizsäcker. In C. de Sá, F. Ferretti, \& M. A. Busato (Orgs.). Ensaios contemporâneos em saúde: uma perspectiva interdisciplinar (pp. 13-31). Chapecó, SC: Argos/Unochapecó.

Rocha, A. P. R., \& Garcia, C. A. (2008). A adolescência como ideal cultural contemporâneo. Psicol. Cienc. prof., 28(3), 622-631. ISSN 1414-9893. Recuperado de: <http://dx.doi.org/10.1590/S1414-98932008000300014>.

Schotte, J. (1985). Une penseé du clinique - L'Oeuvre de Viktor von Weisäcker, notas dirigidas por Philipe Lekeuche e revistas pelo autor, por ocasião do Curso de Questions Approfondies de psycologie clinique 1984-85, Louvain - La Neuve - Bélgica, Centro de Psychologie Clinique UCL. [Texto inédito]

Searle, J. R. (1984). Os actos de fala. Coimbra, PT: Livraria Almedina. (Trabalho original publicado em 1969).

Szondi, L. (1975). Introdução à psicopatologia do destino: liberdade e compulsão no destino do homem, na escolha da profissão, amigos, esposa, doenças. São Paulo, SP: Manole.

Vale, H. F. de S. da C., \& Martins, F. M. de M. C. (2017). Eficácia simbólica da promessa em psicoterapia com adolescentes. Revista Latinoamericana de Psicopatologia Fundamental, 20(4), 641-655. Recuperado de: <http://dx.doi. org/10.1590/1415-4714.2017v20n4p641.2>.

Weizsäcker, V. von (2008). "Das pathische Pentagramm" in Warum wird man krank? Ein Lesenbuch Gesammelte). Stuttgart, GER: Suhrkamp Verlag. (Trabalho original publicado em 1947).

Weizsäcker, V. von (1958). Le Cyrle de La Structure (Der Gestaltkreis), Tradução de Michel Foucault e Daniel Rocher. Paris, FR: Desclée De Brouwer.

Weizsäcker, V. von. (1962). El círculo de la forma (Der Gestaltkreis): Teoria de la unidad de percepcion y movimento. Madrid, ESP: Ediciones Morata.

Weizsäcker, V. von (1987). Begegnungen und Entscheidungen. In Gesammelte Schriften (Vol. 1). Frankfurt am Main, GER: Suhrkamp Verlag. (Trabalho original publicado em 1945).

Winnicott, D. W. (2005a). Privação e delinquência. São Paulo, SP: Martins Fontes. 
Winnicott, D. W. (2005b). A família e o desenvolvimento individual. Porto Alegre, RS: Artes Médicas.

\section{Resumos}

(Promises and pathic verbs in adolescence: A possible reinterpretation of the Freudian moral and super-ego)

This article addresses the implication and role of modal/pathic verbs in the construction of promises and their relationship with the superego modalities of adolescence today. Promises are here understood as a commitment made via language and they may be used as effective devices to understand superego modalizations of adolescents. The super-ego, in turn, is perceived as the main (dis) organizer of the drive modalization represented by the verbs. We assume that the verb carries the drive and also assembles the human intrapsychic forum. Thus, to understand how adolescents refer to verbs may help to understand their conflicts with moral and drive which come up in the face of our current culture.

Key words: Adolescence, promise, pathic verbs, super-ego

(Promesses et verbes pathiques dans l'adolescence: une possible réinterprétation de la morale e et du surmoi freudiens)

Dans cet article, nous abordons l'implication et le rôle des verbes modaux/ pathiques dans la construction des promesses et leur rapport avec les modalités du surmoi de l'adolescence aujourd'hui. Les promesses, dans le sens où nous les prenons ici, sont comprises comme une action de compromis effectuée par le langage et elles peuvent être utilisées comme des dispositifs efficaces pour comprendre les modalisations du surmoi adolescent. Le surmoi, à son tour, est perçu comme le (dés) organisateur principal de la modalisation pulsionnelle représentée par les verbes. Nous supposons que le verbe porte la pulsion et assemble également le forum intrapsychique humain. Comprendre comment les adolescents se réfèrent aux verbes peut aider à comprendre les conflits moraux et pulsionnels des adolescents construits face à la culture actuelle.

Mots clés: Adolescence, promesse, verbes pathiques, surmoi

(Promesas y verbos pháticos en la adolescencia: una posible reinterpretración de la moral y del superyó freudianos)

En este artículo, abordamos la implicación y el papel de los verbos modales/ pháticos en la construcción de promesas y su relación con las modalidades del superego de la adolescencia actual. Las promesas, en el sentido abordado aquí, 


\section{ARTIGOS}

se entienden como una acción de compromiso realizada a través del lenguaje y se pueden usar como dispositivos efectivos para la comprensión de las modalizaciones del superego adolescente. El superyó, por su parte, se percibe como el principal (des) organizador de la modalización pulsional representada por los verbos. Partimos del principio de que el verbo lleva la pulsión y también ensambla el foro intrapsíquico humano, por lo cual, comprender la forma en la que los adolescentes se refieren a los verbos, puede ayudar a entender sobre los conflictos morales y pulsionales del adolescente construido frente a la cultura actual.

Palabras clave: Adolescencia, promesa, verbos pháticos, superego

Citação/Citation: Vale, H. F. S. C., Freitas, M. H., \& Martins, F. M. M. C. (2020, dezembro). Promessas e verbos páthicos na adolescência: uma possível releitura da moral e do supereu freudiano. Revista Latinoamericana de Psicopatologia Fundamental, 23(4), 689-710. http:// dx.doi.org/10.1590/1415-4714.2020v23n4p689.2.

Editora/Editor: Profa. Dra. Sonia Leite

Submetido/Submitted: 31.1.2020/ 1.31.2020 Aceito/Acepted: 19.7.2020/ 7.19.2020

Copyright: (C) 2009 Associação Universitária de Pesquisa em Psicopatologia Fundamental/ University Association for Research in Fundamental Psychopathology. Este é um artigo de livre acesso, que permite uso irrestrito, distribuição e reprodução em qualquer meio, desde que o autor e a fonte sejam citados / This is an open-access article, which permits unrestricted use, distribution, and reproduction in any medium, provided the original authors and sources are credited.

Financiamento/Funding: Este trabalho recebeu apoio do Conselho Nacional de Desenvolvimento Científico e Tecnológico - CNPq (Brasília, DF, Br) / This work is supported by Conselho Nacional de Desenvolvimento Científico e Tecnológico - CNPq (Brasília, DF, Br).

Conflito de interesses/Conflict of interest: Os autores declaram que não há conflito de interesses. / The authors declare that there is no conflict of interest. 
Hellen Fonseca de Sousa da Costa Vale

Psicóloga Clínica; Doutora em Psicologia pela Universidade Católica de Brasília - UCB (Brasília, DF, Br).

CAS Chácara 64 lote 03B - Vicente Pires

72001-590 Brasília, DF, Br

hfsousa2010@gmail.com

https://orcid.org/0000-0003-0703-8709

\section{Marta Helena de Freitas}

Doutora em Psicologia Clínica e da Cultura pela Universidade de Brasília (Brasília, DF, $\mathrm{Br}$ ), com pós-doutoramentos em Psicologia Intercultural (Universidade do Porto, Portugal) e Psicologia da Religião (University of Kent at Canterbury e University of Walles Trinity Saint David, UK). Professora-pesquisadora do Programa de Pós-Graduação em Psicologia da Universidade Católica de Brasília - UCB (Brasília, DF, Br).

SQNW 309, bl. K, apto 629. Setor Noroeste

70678-155 Brasília, DF, Br.

mhelenadefreitas@gmail.com

https://orcid.org0000-0003-1552-6016

\section{Francisco Moacir de Melo Catunda Martins}

Psicanalista; Psiquiatra; Psicólogo; Professor Titular aposentado no departamento de Psicologia da Universidade de Brasília - UnB (Brasília, DF, Br).

SHGN 716 Bloco P Casa 30 - Asa Norte

70.770-746 Brasília, DF, Br.

fracatmartins@icloud.com

https://orcid.org/0000-0001-5714-2382

This is an open-access article, which permits unrestricted use, distribution, the original authors and sources are credited. 